\title{
Monoamine and neuroendocrine gene-sets associate with frustration-based aggression in a gender-specific manner
}

\author{
Marjolein M.J. van Donkelaar a,b,*, Martine Hoogman ${ }^{\mathrm{a}, \mathrm{b}}$, \\ Elena Shumskaya ${ }^{a, f}$, Jan K. Buitelaar ${ }^{b, c, d}$, Janita Bralten ${ }^{a, b}$, \\ Barbara Franke a,b,e
}

${ }^{a}$ Radboud university medical center, Department of Human Genetics (855); PO Box 9101, 6500 HB

Nijmegen, The Netherlands

${ }^{\mathrm{b}}$ Donders Institute for Brain, Cognition and Behaviour, Radboud University, Nijmegen, The Netherlands

'Department of Cognitive Neuroscience, Radboud university medical center Nijmegen, The Netherlands

${ }^{\mathrm{d}}$ Karakter Child and Adolescent Psychiatry, Radboud university medical center Nijmegen, The

Netherlands

e Department of Psychiatry, Radboud university medical center, Nijmegen, The Netherlands

f Donders Centre for Cognitive Neuroimaging, Donders Institute for Brain, Cognition and Behaviour,

Radboud University, Nijmegen, The Netherlands

Received 2 May 2017; received in revised form 5 November 2017; accepted 9 November 2017

\section{KEYWORDS \\ Aggression; \\ Genetics; \\ Factor analysis; \\ Serotonin; \\ Dopamine; \\ Neuroendocrine system}

\begin{abstract}
Investigating phenotypic heterogeneity in aggression and understanding the molecular biological basis of aggression subtypes may lead to new prevention and treatment options. In the current study, we evaluated the taxonomy of aggression and examined specific genetic mechanisms underlying aggression subtypes in healthy males and females. Confirmatory Factor Analysis (CFA) was used to replicate a recently reported three-factor model of the Reactive Proactive Questionnaire (RPQ) in healthy adults ( $n=661$; median age 24.0 years; $41 \%$ male). Gene-set association analysis, aggregating common genetic variants within (a combination of) three molecular pathways previously implicated in aggression, i.e. serotonergic, dopaminergic, and neuroendocrine signaling, was conducted with MAGMA software in males and females separately (total $n=395$ ) for aggression subtypes. We replicate the three-factor CFA model of the RPQ, and found males to score significantly higher on one of these factors compared to
\end{abstract}

\footnotetext{
* Corresponding author at: Radboud University Medical Center, Department of Human Genetics (855); PO Box 9101, 6500 HB Nijmegen, The Netherlands.

E-mail address: Marjolein.vanDonkelaar@radboudumc.nl (M.M.J. van Donkelaar).
} 
females: proactive aggression. The genetic association analysis showed a female-specific association of genetic variation in the combined gene-set with a different factor of the RPQ; reactive aggression due to internal frustration. Both the neuroendocrine and serotonergic gene-sets contributed significantly to this association. Our genetic findings are subtype- and sex-specific, stressing the value of efforts to reduce heterogeneity in research of aggression etiology. Importantly, subtype- and sex-differences in the underlying pathophysiology of aggression suggest that optimal treatment options will have to be tailored to the individual patient. Male and female needs of intervention might differ, stressing the need for sex-specific further research of aggression. Our work highlights opportunities for sample size maximization offered by population-based studies of aggression.

(c) 2017 Elsevier B.V. and ECNP. All rights reserved.

\section{Introduction}

Aggression has been defined as any behavior directed toward the goal of causing harm or injury to others (Baron and Richardson, 1994). From an evolutionary perspective, aggressive behaviors can be adaptive and have an important role in survival and competition for resources (Georgiev et al., 2013). In modern societies, aggression often is maladaptive and associated with negative consequences, causing psychological and somatic burden to victims as well as to aggressive individuals themselves (Fergusson et al., 2005; Reef et al., 2010). Aggression poses a substantial financial burden on society, for example caused by increased legal costs and work absence (WHO, 2007). A better understanding of the subtypes and etiology of aggression is needed to facilitate prevention and to improve treatment options (Fergusson et al., 2005). Given that about half of the variance in aggressive behaviors may be explained by genetic influences (Tuvblad and Baker, 2011; Veroude et al., 2016), studying the molecular genetics underlying these behaviors can provide important mechanistic insights. Research into aggression etiology is, however, complicated by several factors, including considerable phenotypic as well as genetic heterogeneity and the existence of sex differences in aggressive behaviors (Baker et al., 2008; Georgiev et al., 2013).

\subsection{Subtypes of aggression}

Heterogeneity in the etiology of aggression may be parsed by considering subtypes. Different classification systems have been proposed; one based on biological hypotheses is the distinction of proactive and reactive aggression (Dodge and Coie, 1987). Proactive aggression, also referred to as instrumental aggression, is goal-oriented, organized behavior often associated with low autonomic arousal and affect. Reactive aggression on the other hand, is also known as impulsive or affective aggression, and occurs in response to provocation or a negative emotional state (Raine et al., 2006; Stanford et al., 2003). Importantly, the subtypes have been associated with distinct behavioral, neurocognitive, and neural characteristics. For example, proactive aggression has been related to psychopathic traits and delinquent behavior (Cima and Raine, 2009; Cima et al., 2013), while the reactive subtype of aggression has been associated with impulsivity, anxiety, and hostile interpretation bias
(Brugman et al., 2015; Bubier and Drabick, 2009). Twin studies showed slightly higher heritability estimates for proactive than reactive aggression (Baker et al., 2008; Brendgen et al., 2005; Tuvblad et al., 2009). The two aggression subtypes may have partially distinct genetic contributions. Serotonergic and dopaminergic neurotransmission may regulate both reactive and proactive aggression, whereas endocrine signaling seems to be more involved in the regulation of reactive aggression, e.g. through modulation of impulsivity and the stress response (Waltes et al., 2015). Recently, a further subdivision of reactive aggression has been proposed based on an exploratory factor analysis of the Reactive Proactive Questionnaire (RPQ). This analysis was conducted in a sample of adolescents (71.6\% male), who were referred to clinical services for externalizing behavior problems (Smeets et al., 2016). Besides a proactive factor, reactive aggression was further subdivided into a subtype associated with external provocation or threat and another one associated with internal frustration. Improved fit indices for this three factor model compared to the original twofactor model were also reported based on an adult, malesonly sample recruited partly in forensic psychiatric in- and outpatient clinics and partly from the general population. (Brugman et al., 2016). The reactive subtypes differed in their associated behavioral correlates, which suggests that the three-factor model may further reduce phenotypic heterogeneity and facilitate the search for genes involved in the etiology of aggression.

\subsection{Sex differences in aggression}

The most convincing observation supporting the existence of sex differences in aggression is the difference in crime rate statistics between males and females. Females are vastly less likely to commit serious offenses than males, and males are more likely to display antisocial behavior than females (Stephenson et al., 2014). Males are also overrepresented in aggression-related disorders such as conduct disorder $(C D)$, where the gender ratio is approximately 2.5 (Hill, 2002). Importantly, sex differences are also found in the type of aggressive behavior displayed (Collett et al., 2003). The clear gender-specificity of aggression is thought to have evolved by sexual selection, and to reflect differences in optimal strategies in the competition for resources for males and females (Georgiev et al., 2013). Sex differences in heritability estimates have been observed in some 
but not all of the aggression twin studies conducted to date, with higher heritability estimates for boys than girls, when self-report measures were assessed (Baker et al., 2008; Wang et al., 2013). Incorporation of sex in aggression studies may be essential to identify the underlying biological mechanisms of aggressive behaviors.

\subsection{Biological systems}

The biological systems most investigated in the context of aggression phenotypes (as well as related traits such as mood disturbances and impulsivity) are the monoaminergic neurotransmitter systems related to serotonin and dopamine and the neuroendocrine system. Multiple reviews to date discuss these systems in the context of aggression and list the candidate genes that have been investigated for association with aggressive behaviors (Pavlov et al., 2012; Veroude et al., 2016; Waltes et al., 2015).

The serotonergic system is hypothesized to play a key role in aggression due to its influence on functions including social cognition, emotional regulation, and cognitive control (Lesch et al., 2012). Both human and animal studies link genes within these systems to aggressive behavior. For example, the serotonin transporter gene (SLC6A4) is one of the most investigated candidate genes for aggression. Variation in the serotonin receptor 2B gene $(5-H T 2 B)$ has been associated with violent impulsivity in a Finnish population, and 5-HT2B and 5-HT1B knockout studies in mice implicate these genes in aggression and/or impulsivity (Bevilacqua et al., 2010; Nautiyal et al., 2015). While candidate genetic association studies have often produced equivocal results, investigations measuring levels of the serotonin metabolite 5-HIAA in cerebrospinal fluid, e.g. (Brown et al., 1979; Coccaro and Lee, 2010), or manipulating central serotonin function through tryptophan depletion/loading, e.g. (Bjork, 2000), have revealed a highly significant relationship between serotonin availability and aggression (Rosell and Siever, 2015). Dopamine is relevant for understanding aggression because of its effects on reward, motivated behavior, and decision making (Costa et al., 2012). While studies of dopamine manipulation have mostly been conducted in animals, the involvement of dopamine in aggression is also evidenced by the fact that in humans, D2-receptor antagonists have been used effectively to treat aggressive behavior (Nelson and Trainor, 2007). Additional evidence linking the serotonergic and dopaminergic neurotransmitter systems comes from genetic association studies of the MAOA gene. This $X$-linked gene encodes the enzyme monoamine oxidase A, which breaks down both serotonin and dopamine, and has been robustly associated with aggression, especially in the context of stress and maltreatment (Brunner et al., 1993; Caspi et al., 2002; Byrd and Manuck, 2014). The third system implicated in aggression is the neuroendocrine system, including both stress-related hypothalamic-pituitary-adrenal (HPA) axis signaling and sex-hormone-related hypothalamopituitary-gonadal (HPG) axis signaling. As early life stress is known to increase risk for the development of mood and aggression-related disorders (Agid et al., 1999; Éthier et al., 2004; Fonagy, 2006; Heim et al., 2001), the neuroendocrine stress response with its genetic components is a major candidate system for the development of aggressive behaviors.
The relation of the HPA axis to aggression has been well established, especially through animal studies (Veenema, 2009). Also in humans, cortisol levels have been related to aggression repeatedly (Alink et al., 2012; Loney et al., 2006; Popma et al., 2007; Shirtcliff et al., 2005; van Bokhoven et al., 2004). The HPG axis involves signaling between hypothalamus, pituitary, and the gonadal glands, which produce estrogen and testosterone. Testosterone levels have been related to human aggression (Book et al., 2001; Brown et al., 2008; Chichinadze et al., 2010; Yu and Shi, 2009) and it has been hypothesized that especially the interplay between cortisol and sex steroids is important in determining aggression liability (Pavlov et al., 2012; Terburg et al., 2009).

Extensive reviews of aggression candidate gene studies have recently been published (Fernandez-Castillo and Cormand, 2016; Pavlov et al., 2012; Veroude et al., 2016; Waltes et al., 2015). Although a moderate number of studies has been conducted, a meta-analysis of individual candidate variants did not reveal any significant associations with aggressive behavior (Vassos et al., 2014). One reason for this may be the complex genetic background of aggression in most people. While a few monogenic aggression disorders caused by rare genetic variations with a high effect size exist (Brunner et al., 1993; Zhang-James et al., 2016), aggression in the population has a complex and polygenic genetic background, which can be aggravated by environmental factors (Veroude et al., 2016).

In the current study, we assessed the genetic mechanisms underlying aggression subtypes in the general population. Firstly, we aimed to verify the existence of three aggression subtypes in adult males and females from the general population based on the RPQ. Second, we aimed to assess the association of common genetic variants in the three biological systems with most evidence for a role in aggression, i.e. the serotonergic system, the dopaminergic system, and the neuroendocrine system with the different subtypes. We aimed to maximize power for finding genetic associations by (1) parsing phenotypic heterogeneity through differentiating between subtypes, (2) by assessing males and females separately, and (3) by combining genetic variants in a geneset analysis (Bralten et al., 2011; Bralten et al., 2013; Naaijen et al., 2017).

\section{Experimental procedures}

\subsection{Sample}

The investigated sample consisted of participants of the Brain Imaging Genetics (BIG) study conducted at the Donders Institute for Brain, Cognition and Behaviour (Franke et al., 2010). The BIG study consists of self-reported healthy adults, who participated in smaller-scale imaging studies at the institute and gave consent to be included in the BIG study. Saliva samples for genetic testing were collected, and an internet-based test-battery of questionnaires was applied. The Reactive Proactive Questionnaire (RPQ; Raine et al., 2006) was available for 661 participants (age range 18-45 years). Of those, 395 participants had genome-wide genotyping data available.

All participants were of Caucasian descent and were screened using a self-report questionnaire for the following exclusion criteria before study participation: a history of somatic disease potentially 
affecting the brain, current or past psychiatric or neurological disorder, medication (except hormonal contraceptives) or illicit drug use during the past 6 months, history of substance abuse, current or past alcohol dependence, pregnancy, lactation, menopause, and magnetic resonance imaging contraindications (Gerritsen et al., 2012). All participants gave written informed consent, and the study was approved by the regional ethics committee.

\subsection{Aggression questionnaire}

The Reactive Proactive Questionnaire (RPQ) was used to assess subtypes of aggression (Raine et al., 2006). The RPQ is a self-report questionnaire consisting of 23 items. For each item, subjects are asked to indicate, how often they have engaged in a given type of behavior. Items are rated on a three-point Likert scale ('never' $=0$, 'sometimes' $=1$, 'often' $=2$ ). Responses were summed to yield the three factors that best described the RPQ in an earlier exploratory factor analysis (Smeets et al., 2016): 'proactive aggression', 'reactive aggression due to internal frustration', and 'reactive aggression due to external provocation'. Items relating to each subtype can be found in Supplementary Table 1.

\subsection{Factor analysis}

Confirmatory factor analysis (CFA) was conducted using Mplus (version 6.11; https: //www.statmodel.com/). Results were considered acceptable, when both the Comparative Fit Index (CFI) and the Tucker-Lewis Index (TLI) exceeded .90 (with values closer to 1 indicating better fit), and the Root Mean Squared Error of Approximation (RMSEA) was below .06 (with values closer to 0 indicating better fit) (Hu and Bentler, 1999; Smeets et al., 2016).

\subsection{Genotyping and imputation}

Genetic analyses were carried out at the Department of Human Genetics of the Radboud University Medical Center. Saliva samples were collected using Oragene kits (DNA Genotek, Kanata, Canada), and genomic DNA was extracted as specified by the manufacturer. Genome-wide genotyping was performed on two different platforms, Affymetrix Genome-Wide Human SNP Array 6.0 (Affymetrix Inc., Santa Clara, CA, USA) $(\mathrm{n}=243)$ and the Infinium PsychArray24 v1.1 BeadChip (http://www.illumina.com/products/psycharray. html) $(n=152)$. Genotype calling and quality control steps are described in the Supplementary Information. MACH software was used for haplotype phasing and minimac for the final imputation (Howie et al., 2012; Li et al., 2010), with 1000 Genomes Phase 1.v3 reference data (Abecasis et al., 2012).

\subsection{Gene-set selection and construction}

Gene selection for aggression candidate gene-sets involved in neuroendocrine signaling, dopamine neurotransmission, and serotonin neurotransmission was performed using the Ingenuity Pathway Analysis (IPA) software (http://www.ingenuity.com). Ingenuity draws on the Ingenuity Knowledge Base which is based on information from published literature as well as on various other sources including gene expression and gene annotation databases. The serotonergic gene-set contained genes involved in serotonergic receptor signaling and de dopaminergic gene-set contained genes involved in dopaminergic receptor signaling. The neuroendocrine gene-set contained genes involved in corticotropin-releasing hormone, glucocorticoid, androgen, and estrogen signaling. An overview of selected genes can be found in Table 1. All single nucleotide polymorphisms (SNPs) in or within $100 \mathrm{~kb}$ flanking regions of the genes (also capturing regulatory sequences) were selected for analysis.

\subsection{Gene-set analyses}

Genome-wide association analyses for the three subtypes of aggression were performed using Mach2qtl/Mach2dat (Li et al., 2010), adjusting for age, age ${ }^{2}$, and four population components derived from multidimensional scaling analysis. For RPQ proactive aggression scores only, scores were dichotomized into high- and lowscoring (score $\geq 2$ and score $\leq 1$, respectively), because of a highly positively skewed distribution (Supplementary Figure 1). Separate analyses were run for males and females, and for subjects genotyped on the two different genotyping arrays. SNPs with low imputation quality $\left(R^{2}<0.6\right)$ and minor allele frequency of less than $1 \%$ were filtered out. Resulting SNP p-values for each of the traits were used to run gene-set analysis using MAGMA v1.04 (de Leeuw et al., 2015). SNPs were mapped onto genes using 1000 Genomes Phase $1 . v 3$ reference data followed by computation of gene $p$ values. Fixed-effects meta-analysis of the output of the two genotyping arrays was run using the weighted Stouffer's Z method as implemented in MAGMA. We first assessed association of all three gene-sets combined on the three aggression subtypes. The MAGMA competitive gene-set analysis was used to assess association, which will correct for confounding due to gene-size, gene density, differential sample size and the log of those values. Results of the self-contained test option in MAGMA, which tests whether a signal is present in the aggregated set of SNPs compared with a signal being present by random chance, are also reported for comparability with previously used methods in literature. This association method does not take into account gene-size and gene density, or whether the association of the gene-set is greater than that of other genes. Results were considered significant if they reached the Bonferroni-corrected $P$-value-threshold for testing of three aggression subtypes and two sexes ( $P$-value threshold $=0.05 / 6=0.0088$ ). For significant associations observed in the competitive test, we performed post-hoc tests to localize effects amongst the three separate gene-sets and individual genes within the sets. An additional post-hoc analysis assessed association of all three gene-sets combined using the two-factor classification of reactive and proactive aggression (Supplementary Information).

\section{Results}

The general characteristics of our sample of 661 participants and the genotyped sample of $n=395$ are shown in Table 2. The tree factor model of the RPQ, consisting of a proactive factor, a reactive factor due to internal frustration, and a reactive factor due to external provocation or threat, showed a good model fit in the healthy adults (RMSEA 90\% Cl: .041-.051, RMSEA: .046, CFI: .915, TLI: .905), Cronbach's alpha $=0.687$ (proactive), 0.663 (reactive internal frustration), 0.684 (reactive external provocation). An overview of fit-measures for one-, two-, and three-factor models are provided in Supplementary Table 2. In line with earlier studies, inter-correlations between the three investigated aggression subtypes were moderate and significant in our investigated sample $(.436 \geq r \leq .574)$, marking them as distinguishing but correlated dimensions of aggression.

Gene-set association analysis with aggression subtypes was conducted in the 395 subjects with genotyping information available. Males scored significantly higher on proactive aggression than females in the genotyped $(\mathrm{t}(393)=5.97, \mathrm{P}$ $<0.001)$ as well as the phenotyped cohort $(\mathrm{t}(659)=6.59$, $\mathrm{P}<0.001$ ). A total of 483 unique autosomal genes were selected for the combined dopaminergic, serotonergic, and neuroendocrine gene-set. Twenty additional genes, either 
Table 1 Selected genes for each of the three gene-sets (serotonergic, dopaminergic, neuroendocrine).

\begin{tabular}{|c|c|c|c|c|c|c|c|c|c|c|}
\hline \multicolumn{11}{|c|}{ Serotonergic gene-set ( $n=43$ genes) } \\
\hline $5 H T 1 A$ & $5 H T 1 B$ & $5 H T 1 D$ & $5 H T 1 E$ & $5 H T 4$ & $5 H T 6$ & $5 H T 7$ & $A D C Y 1$ & $A D C Y 10$ & $A D C Y 2$ & $A D C Y 3$ \\
\hline$A D C Y 4$ & $A D C Y 5$ & $A D C Y 6$ & $A D C Y 7$ & $A D C Y 8$ & $A D C Y 9$ & $D D C$ & GCH1 & GNAS & HTR2A & HTR2B \\
\hline HTR2C & HTR3A & HTR3B & HTR3C & HTR3D & HTR3E & HTR5A & IL4I1 & MAOA & MAOB & $P C B D$ \\
\hline PTS & QDPR & SERT & SLC18A1 & SLC18A2 & SLC18A3 & SMOX & $S P R$ & TPH1 & $\mathrm{TPH} 2$ & \\
\hline
\end{tabular}

Dopaminergic gene-set ( $n=77$ genes)

\begin{tabular}{|c|c|c|c|c|c|c|c|c|c|c|}
\hline$\overline{A D C Y 1}$ & $A D C Y 10$ & $A D C Y 2$ & $\overline{A D C} C 3$ & $A D C Y 4$ & $A D C Y 5$ & $A D C Y 6$ & $A D C Y 7$ & $A D C Y 8$ & $A D C Y 9$ & CALY \\
\hline COMT & DAT & $D D C$ & DRD1 & DRD2 & DRD3 & DRD4 & DRD5 & GCH1 & GNAS & IL4I1 \\
\hline MAOA & MAOB & NCS1 & PCBD & PPM1J & PPM1L & PPP1CA & $P P P 1 C B$ & PPP1CC & $P P P 1 R 1 B$ & PPP1R10 \\
\hline$P P P 1 R 11$ & $P P P 1 R 12 A$ & PPP1R14A & $P P P 1 R 14 B$ & $P P P 1 R 14 C$ & PPP1R14D & PPP1R3A & PPP1R3C & $P P P 1 R 3 D$ & $P P P 1 R 7$ & $P P P 2 C A$ \\
\hline$P P P 2 C B$ & $P P P 2 R 1 A$ & $P P P 2 R 1 B$ & $P P P 2 R 2 A$ & $P P P 2 R 2 B$ & $P P P 2 R 2 C$ & $P P P 2 R 3 A$ & PPP2R3B & $P P P 2 R 4$ & $P P P 2 R 5 A$ & $P P P 2 R 5 B$ \\
\hline$P P P 2 R 5 C$ & $P P P 2 R 5 D$ & PPP2R5E & PRKACA & PRKACB & PRKACG & PRKAG1 & PRKAG2 & PRKAR1A & PRKAR1B & PRKAR2A \\
\hline PRKAR2B & $P R L$ & PTH & PTS & $Q D P R$ & SLC $18 A 1$ & SLC18A2 & SLC18A3 & SMOX & $S P R$ & $\mathrm{TH}$ \\
\hline
\end{tabular}

Neuroendocrine gene-set ( $n=426$ genes)

\begin{tabular}{|c|c|c|c|c|c|c|c|c|c|c|}
\hline$\overline{A 2 M}$ & CB1 & EP300 & GNB5 & HSP4O & KRAS & MEKK1 & PIK $3 C 2 A$ & PRKAA2 & SMAD2 & TAF7 \\
\hline$A C T B$ & $C B P$ & $E R$ & GNG10 & HSP90AA1 & KRT1 & MKP1 & PIK3C2B & PRKAB1 & SMAD3 & TAF7L \\
\hline$A C T L 6 B$ & CC10 & $E R C C 2$ & GNG11 & HSP90AB1 & KRT32 & MMP1 & PIK3C2G & PRKAB2 & SMAD4 & TAF9 \\
\hline$A D C Y 1$ & CCL11 & $E R C C 3$ & GNG12 & HSP9OB1 & KRT35 & MNAT1 & PIK3C3 & PRKACA & SMARCA2 & TAF9B \\
\hline$A D C Y 2$ & CCL13 & $E R \beta$ & GNG13 & HSPA14 & KRT36 & $M R$ & PIK3CA & PRKACB & SMARCA4 & TAK1 \\
\hline$A D C Y 3$ & $C C L 2$ & FASLG & GNG2 & HSPA1A & MAP2K1 & MRAS & PIK3CB & PRKACG & SMARCB1 & TAT \\
\hline$A D C Y 5$ & $C C L 3$ & FCGR1 & GNG3 & HSPA1B & $M A P 2 K 2$ & NCOA2 & PIK3CD & PRKAG1 & SMARCC1 & TBP \\
\hline$A D C Y 6$ & CCL5 & $F G G$ & GNG4 & HSPA1L & $M A P 2 K 4$ & NCOA3 & PIK3CG & PRKAG2 & SMARCC2 & TEBP \\
\hline$A D C Y 7$ & CCNC & FKBP51 & GNG5 & HSPA2 & $M A P 2 K 7$ & NCOR1 & PIK3R1 & PRKAR1A & SMARCD1 & TFIIB \\
\hline$A D C Y 8$ & CCND1 & FKBP52 & GNG7 & HSPA4 & MAPK1 & NCOR2 & PIK3R2 & PRKAR1B & SMARCD2 & TGFB1 \\
\hline$A D C Y 9$ & $\mathrm{CCNH}$ & FOS & $G R$ & HSPA5 & MAPK10 & NFAT5 & PIK3R3 & PRKAR2A & SMARCD3 & TGFB2 \\
\hline ADRB2 & CD163 & FOX03A & GRB2 & HSPA6 & MAPK11 & NFATC 1 & PIK3R4 & PRKAR2B & SMARCE1 & TGFB3 \\
\hline$A G T$ & $C D 247$ & $G 6 P C$ & GTF2A1 & HSPA8 & MAPK12 & NFATC2 & PIK3R5 & PRKCA & SMILE & TGFBR 1 \\
\hline$A K T 1$ & $C D 3 D$ & G6PC2 & $G T F 2 A 2$ & HSPA9 & MAPK13 & NFATC3 & PIK3R6 & PRKCB & SOS1 & TGFBR2 \\
\hline$A K T 2$ & CD3E & G6PC3 & GTF2E1 & ICAM1 & MAPK14 & NFATC4 & PLAU & PRKCD & SOS2 & THRAP3 \\
\hline AKT3 & $C D 3 G$ & GILZ & GTF2E2 & IFNG & MAPKЗ & NFKB1 & PLCG1 & PRKCE & SRA1 & $T N F$ \\
\hline$A N F$ & CDK7 & GLI1 & GTF2F1 & IGFBP1 & MAPK8 & NFKB2 & PLCG2 & PRKCG & $S R C$ & $T R A$ \\
\hline$A N X A 1$ & CDK8 & GLI2 & GTF2F2 & $I K B K B$ & MAPK9 & $N F K B I A$ & POLR2A & PRKCH & $S R C-1$ & TRAF2 \\
\hline$A R$ & CDKN1A & GLI3 & GTF2H1 & IKBKE & MED10 & NFKBIB & POLR2B & PRKCI & $S R Y$ & TRAF6 \\
\hline ARA55 & CDKN1C & GNA11 & GTF2H2 & IKBKG & MED12 & NFKBIE & POLR2C & PRKCQ & STAT1 & $T R B$ \\
\hline ARA70 & $C E B P \alpha$ & GNA12 & GTF2H3 & $1 / 10$ & MED12L & NIK & POLR2D & PRKCZ & STAT3 & TRRAP \\
\hline ARID1A & $C E B P \beta$ & GNA13 & GTF2H4 & IL13 & MED13 & NOS1 & POLR2E & PRKD1 & STAT5A & TSG 101 \\
\hline ARID2 & CHP1 & GNA14 & GTF2H5 & IL1B & MED13L & NOS2 & POLR2F & PRKD3 & STAT5B & $U B C 9$ \\
\hline ATF2 & CHUK & GNA15 & GUCY1A2 & $I L 1 R 2$ & MED15 & NOS3 & POLR2G & PRKDC & SUMO1 & VCAM1 \\
\hline ATF4 & $\operatorname{cox} 2$ & GNAl1 & GUCY1A3 & IL1RA & MED16 & NPR1 & POLR2H & $P R L$ & $T A B 1$ & VIPR1 \\
\hline ATM & CREB & GNAI2 & GUCY1B3 & IL2 & MED17 & NPR2 & POLR2I & RAC1 & $T A F 1$ & YWHAH \\
\hline$B A G 1$ & $C R H$ & GNAI3 & GUCY2C & IL3 & MED18 & NROB2 & POLR2J & $R A F 1$ & TAF10 & \\
\hline$B C L 2$ & CRHR1 & GNAL & GUCY2D & IL4 & MED2O & NR4A1 & POLR2J2 & $R E A$ & TAF11 & \\
\hline$B C L 2 L 1$ & CRHR2 & GNAO1 & GUCY $2 F$ & IL5 & MED21 & NRAS & POLR2J3 & $R E L A$ & TAF12 & \\
\hline$B D N F$ & CSF2 & GNAQ & H3F3A & IL6 & MED23 & OPN1SW & POLR2K & RIP140 & TAF13 & \\
\hline$B G L A P$ & CSN2 & GNAS & $H 3 F 3 B$ & IL8 & MED24 & PAl1 & POLR2L & RRAS & TAF15 & \\
\hline$B R A F$ & CTBP1 & GNAT1 & HBO1 & ITPR1 & MED27 & PBRM1 & POMC & RRAS2 & TAF1L & \\
\hline BRD7 & CTBP2 & GNAT2 & $H D A C 3$ & ITPR2 & MED30 & $P B X$ & POU2F1 & RTA & TAF2 & \\
\hline CALM1 & CXCL2 & GNAZ & HIST1H3C & ITPR3 & MED31 & $P C A F$ & POU2F2 & RUNX2 & TAF3 & \\
\hline CALM2 & $D A X 1$ & GNB1 & $\mathrm{HIST} 2 \mathrm{H} 3 \mathrm{C}$ & $I V L$ & MED4 & $P C K 1$ & РPР $3 C A$ & SELE & TAF4 & \\
\hline CALM3 & $D D \times 5$ & GNB1L & HIST3H3 & JAK1 & MED6 & PCK2 & РРРЗСВ & SGK1 & TAF4B & \\
\hline CALML5 & DPF1 & GNB2 & $H L T F$ & JAK2 & MEF2A & PELP1 & РРPЗСС & SHARP & TAF5 & \\
\hline$C A L R$ & DRIP150 & GNB2L1 & $H M G-1$ & JAK3 & MEF2B & $P G C-1$ & PPP3R1 & $S H B G$ & TAF5L & \\
\hline CAMK4 & DRIP205 & GNB3 & HNRNPD & JUN & $M E F 2 C$ & $P G R$ & PPP3R2 & $S H C$ & TAF6 & \\
\hline CARM1 & $E L K 1$ & GNB4 & HRAS & JUND & MEF2D & PHF10 & PRKAA1 & SLPI & TAF6L & \\
\hline
\end{tabular}

Bold: Located on the $X$ - or Y-chromosome or not captured by the genotyping array. The selected dopamine and serotonin pathway-sets overlap in 24 genes. The neuroendocrine set overlaps with the serotonin-set in 9 genes and with the dopamine-set in 19 genes. 
located on the X- and Y-chromosome or not captured by the array, could not be included in the analysis (Table 1).

Association analysis of all three gene-sets combined with each of the three aggression subtypes was performed for males and females separately (Table 3). In females, the combined gene-set was significantly associated with frustration-based reactive aggression, but not with reactive aggression due to external provocation/threat or with proactive aggression scores. The significant association of the combined set with reactive aggression due to internal frustration as measured by competitive testing was observed for both genotyping arrays ( $P_{\text {Affymetrix_competitive }}=1.397 e-03$ and $\mathrm{P}_{\text {Infinium_competitive }}=2.175 \mathrm{e}-04$, respectively), showing replicability of the finding. In males, the combined gene-set was not associated with any of the aggression subtypes using competitive tests. Post-hoc analysis results, comparing our main association results with associations based on the two-factor model of reactive and proactive aggression, can be found in the Supplementary Information. Self-contained test results were highly significant for proactive aggression scores in both males and females.

For the significant finding for reactive aggression due to internal frustration in females, we subsequently explored contributions of the three separate gene-sets and of individual genes within these sets. As shown in Table 4, these post-hoc analyses showed that the neuroendocrine and the serotonergic gene-set were independently contributing to the association. Separate tests of each of the subsets of the neuroendocrine pathway (corticotropin-releasing hormone, glucocorticoid, estrogen, and androgen signaling cascades) provided evidence for contributions of each of these cascades to the association, with lowest p-values for glucocorticoid and androgen signaling (Table 4). No single genes showed significant associations after Bonferroni correction for 40 (serotonin), 73 (dopamine) and 411 (neuroendocrine) genes tested (Supplementary Table 3). The gene with the strongest association in the serotonergic set was the serotonin transporter (SLC6A4, P =0.0098), and the gene with the strongest association in the neuroendocrine set was Cyclin-Dependent Kinase-Activating Kinase Complex Subunit $(\mathrm{CCNH}, \mathrm{P}=0.0004)$.

\section{Discussion}

In the current study, we investigated genetic mechanisms underlying aggression subtypes in the healthy population. Factor analysis confirmed that three correlated but separate dimensions of aggression can be distinguished in healthy adults, using the self-report scale RPQ ('proactive aggression', 'reactive aggression due to internal frustration', and 'reactive aggression due to external provocation'). Aggregated analysis of common variants within monoaminergic and neuroendocrine systems confirmed association of these systems with reactive aggression due to internal frustration in females.

Our results confirming the existence of three distinguishable dimensions of aggression in healthy adults are in line with the previous study investigating alternative factor solutions for the RPQ in adults (Brugman et al., 2016). These authors reported improved fit-indices in exploratory factor 
Table 3 Results for the association of the serotonergic, dopaminergic and neuroendocrine gene-sets combined with three aggression subtypes.

\begin{tabular}{|c|c|c|c|c|}
\hline & \multicolumn{2}{|l|}{ Females } & \multicolumn{2}{|l|}{ Males } \\
\hline & $\mathrm{P}_{\text {competitive }}$ & $P_{\text {self-contained }}$ & $\mathrm{P}_{\text {competitive }}$ & $P_{\text {self-contained }}$ \\
\hline Proactive aggression & 0.316 & $1.12 \mathrm{E}-17$ & 0.043 & $3.20 \mathrm{E}-28$ \\
\hline Reactive internal frustration & $2.275 \mathrm{E}-5^{\mathrm{a}}$ & 5.51E-07 & 0.337 & 0.525 \\
\hline Reactive external provocation & 0.438 & 0.014 & 0.273 & 0.159 \\
\hline
\end{tabular}

Table 4 Results for the association of the serotonergic, dopaminergic, and neuroendocrine gene-sets with reactive aggression due to internal frustration in females.

\begin{tabular}{lll}
\hline & $N_{\text {genes }}$ & $P_{\text {competitive }}$ \\
\hline Serotonin & 40 & $0.016^{\mathrm{a}}$ \\
Dopamine & 73 & 0.059 \\
Neuroendocrine & 411 & $1.147 \mathrm{E}-4^{\mathrm{a}}$ \\
$\quad$ Glucocorticoid & 264 & $8.49 \mathrm{E}-04$ \\
Corticotropin-releasing hormone & 107 & 0.012 \\
Androgen & 110 & $6.46 \mathrm{E}-03$ \\
Estrogen & 123 & 0.023 \\
\hline
\end{tabular}

a Indicates significance after Bonferroni correction for multiple testing ( 3 sets; $P_{\text {threshold }}=0.0167$ )

analysis for the three-factor model compared to the original two-factor model in a males-only sample, recruited partly in forensic psychiatric in- and outpatient clinics and partly from the general population. The first study to find the three-factor structure of the RPQ investigated a younger sample of adolescents, all from clinical samples (Smeets et al., 2016). The current study extends these findings further by showing them to be valid in a highly educated healthy population sample. The specificity of our finding for one of the subtypes, underscores the biological meaningfulness of the observed three-factor structure.

The scores for both reactive subtypes showed a normal distribution in our general population sample; proactive aggression scores were heavily skewed towards the lower end, reflecting the fact that proactive aggression includes more severe behaviors less prevalent in the general population. Proactive aggression scores were significantly higher for males compared to females in our sample of healthy adults. In general, males and females have been shown to differ markedly, both in terms of prevalence and type of aggression displayed. Males are at increased risk of showing overt/physical aggression (Baillargeon et al., 2007; Côté, 2007; Hill et al., 2006), while females may show slightly more indirect aggression (also termed social aggression, relational aggression) compared to males (Card et al., 2008). As proactive aggression is often displayed in a covert manner, and reactive aggressive behavior is more overt, it has been suggested that girls show more proactive aggression and boys show more reactive aggression (Kempes et al., 2005). However, prior studies that have investigated gender-differences in rates of proactive and reactive aggression in children do not confirm this idea. A study of the prevalence of proactive and reactive aggression in a sample of clinically referred children and adolescents did not find gender differences for either of the subtypes (Connor et al., 2003). Studies in non-referred children did find differences, and reported higher rates of both reactive and proactive aggression in boys (Salmivalli and Nieminen, 2002; Baker et al., 2008). It has been suggested that gender-differences may be more pronounced in non-clinical samples (Connor et al., 2003). In our current study of healthy adults, we only find higher proactive (not reactive) aggression scores in males, suggesting that an age effect may also be at play. It has been hypothesized that proactive aggression may become more pronounced at a later age, when cognitive abilities are fully developed and aggressive behaviour may become more calculative in nature (Kempes et al., 2005), a hypothesis that warrants further investigation in future studies.

Our identified association of candidate genetic systems with reactive aggression due to internal frustration in females was driven by variation in serotonergic and neuroendocrine signaling. This finding is in line with literature describing specific effects of serotonin, cortisol, and the sex steroids on aggressive behavior. Indeed, the reported associations of these molecules with aggression often differ as a function of sex and type of aggression studied (reviewed in Rosell and Siever, 2015). For example, higher cortisol reactivity was reported for reactive aggression compared to proactive aggression (Lopez-Duran et al., 2008). One influential theory hypothesizes that a high testosterone/cortisol ratio predisposes to increased aggression, with serotonin modulating the balance between impulsive and instrumental aggression. Specifically, the high testosterone/cortisol ratio is thought to facilitate the fight-flight response by acting on the amygdala-hypothalamus-periaqueductal gray network, while low serotonin reduces inhibitory control by the prefrontal cortex, together leading to increased impulsive, reactive aggression (Montoya et al., 2012). It is interesting to mention that, although not significant after correcting for the number of genes tested, the gene with the strongest association in our serotonergic set was the serotonin transporter (SLC6A4). This is one of the most investigated candidate genes for aggression (Veroude et al., 2016) and has been associated with antisocial behavior in metaanalysis (Ficks and Waldman, 2014).

Our finding for neuroendocrine and serotonergic signaling was specific to one of the two reactive aggression subtypes, i.e. the frustration-based reactive subtype. Although geneset association of reactive aggression as defined by the twofactor classification was also significant (Supplementary Information), providing evidence for the usefulness of the two-factor model in research of aggression etiology, our 
analysis using three subtypes shows that the association was strongly driven by frustration-based reactive aggression and not by threat-based reactive aggression, underscoring the biological meaningfulness of the three-factor structure. This highlights the value of the further reduction of phenotypic heterogeneity for the identification of underlying biological mechanisms of aggression. One of the characteristics of the frustration-based subtype is thought to be an inflexibility to changes in the environment (Smeets et al., 2016). Our specific finding of strong association of frustration-based reactive aggression with neuroendocrine and serotonergic genes may thus arise (partly) from the function of these genes in stress modulation. However, more research is needed to assess the complex interactions and mechanisms through which the investigated systems lead to aggression-related phenotypes. In this context it will be useful to investigate the effects of early environment on the epigenome and the genetic factors moderating these effects (Provencal et al., 2015). Additionally, imaging genetics studies will be instrumental in investigating the modulation of aggression brain circuitry by aggression risk genes (Bogdan et al., 2017; Thompson et al., 2014).

Our findings were female-specific, a possible explanation for which lies in the idea that the signaling and interaction of the endocrine HPA and HPG axes is different between the sexes. For example, the two axes contribute to androgen production in different proportions in the different sexes (Burger, 2002; Montoya et al., 2012). In general, males and females probably developed different aggression strategies during evolution as a result of sex-specific sex hormone signaling (Georgiev et al., 2013). When using self-contained tests, we found a highly significant association of the geneset with proactive aggression scores in both sexes. While no biological inferences can be made regarding the tested systems based on self-contained tests, nominally significant competitive association results for proactive aggression in males might nevertheless potentially point towards a role of the investigated systems in proactive aggression risk in males. The sex-specificity of at least some of our findings forms an important starting point into genetic differences in aggressive behavior between males and females. With most studies to date including male subjects only, the aggression phenotype in females specifically has been understudied and deserves more attention.

This study provides new information on the underlying mechanisms of aggression, thereby facilitating the search for diagnostic, preventive, and treatment options based on understanding biology. Importantly, from a clinical perspective, the sex and subtype specificity of our findings emphasizes the need for individually tailored treatment options. For example, our genetic association results suggest there is a biological aspect to sexual dimorphism. Fundamental differences in underlying pathophysiology may have important consequences for therapeutic interventions, suggesting that male and female needs for intervention might differ markedly.

Our study should be viewed in the context of specific strengths and limitations. One strength of the current study is the large sample size used to verify the factor structure of the RPQ. Moreover, the study addresses three different types of heterogeneity, tackling issues with phenotypic, sex-related, and allelic heterogeneity. By aggregat- ing the effect of multiple genetic variants relating to the biological processes implicated in aggressive behavior, we were able to boost statistical power for finding genetic association (Naaijen et al., 2017). Nevertheless, power of the study provided limited opportunity for an expansion of the number of variables investigated. Future studies should further investigate correlates of female reactive aggression that could serve to explain our main association results. Possible variables of interest are provided by a study by Connor and coworkers (2003), who specifically investigated the correlates of proactive and reactive aggression in males and females separately. They showed that while a large amount of variance in male reactive aggression was mediated by hyperactive/impulsive behaviors, a large amount of explained variance in female reactive aggression was mediated by early traumatic stress (Connor et al., 2003). X- and $Y$-linked genetic variation could not be taken into account in our study, and we were thus unable to include genetic variation in the well-known MAOA gene in the analysis. Including this variation may further improve power of genetic studies, however, the assumed underlying polygenic risk model (many genetic variants, each with small effect size, are assumed to contribute to the phenotype) was sufficiently captured in the current analysis. Our study of aggression was performed in healthy individuals. In doing so, we assumed a model in which patients diagnosed with aggression disorders can be seen as the extremes in a distribution of aggressive traits. Several lines of research have already shown that this model is relevant in other psychiatric traits such as attention-deficit/hyperactivity disorder and autism spectrum disorders (Martin et al., 2014; Middeldorp et al., 2016; Riglin et al., 2016; Robinson et al., 2016). We selected genes based on their implication in aggression disorders, and indeed, were able to find association with aggressive traits in the general population. Showing that common genetic variants underlying aggression phenotypes are similar in typical and psychiatric populations, this offers many possibilities for future research. While recruitment of large clinical cohorts often proves challenging, large population-based samples are much easier to investigate, offering important opportunities for sample size maximization.

We provide evidence for the existence of three correlated but separate dimensions of aggression in healthy adults, and identify variation in neuroendocrine and serotonergic signaling as a biological risk factor involved in the etiology of frustration-based reactive aggression in females. To our knowledge, this is the first study investigating the combined effect of common genetic variants related to monoaminergic and neuroendocrine signaling on aggression subtypes. The findings stress the value of reducing phenotypic and sexrelated heterogeneity in research of aggression etiology, and the opportunities offered by population-based studies of aggression.

\section{Role of funding source}

The authors would like to acknowledge grants supporting their work from the Netherlands Organization for Scientific Research (NWO), i.e. the NWO Brain \& Cognition Excellence Program (grant 433-09-229) and the Vici Innovation Program (grant 016-130-669 to BF). Additional support is 
received from the European Community's Seventh Framework Programme (FP7/2007 - 2013) under grant agreements $\mathrm{n}^{\circ} 602805$ (Aggressotype), $\mathrm{n}^{\circ} 603016$ (MATRICS), $\mathrm{n}^{\circ} 602450$ (IMAGEMEND), and $n^{\circ} 278948$ (TACTICS), and from the European Community's Horizon 2020 Programme (H2020/2014 - 2020) under grant agreements $n^{\circ} 643051$ (MiND) and $n^{\circ}$ 667302 (CoCA). The work was also supported by the ECNP Network ADHD across the Lifespan. This study used the BIG database, which was established in Nijmegen in 2007. This resource is now part of Cognomics, a joint initiative by researchers of the Donders Centre of cognitive Neuroimaging, the Human Genetics and Cognitive Neuroscience departments of the Radboud university medical centre, and the Max Planck Institute for Psycholinguistics. The Cognomics Initiative is supported by the participating departments and centres and by external grants, that is, the Biobanking and Biomolecular Resources Research Infrastructure (Netherlands) (BBMRI-NL), the Hersenstichting Nederland, and the Netherlands Organisation for Scientific Research (NWO). None of the funding sources had a role in study design; in the collection, analysis and interpretation of data; in the writing of the report; and in the decision to submit the paper for publication.

\section{Contributors}

Marjolein M.J. van Donkelaar, Martine Hoogman, Janita Bralten, Jan Buitelaar and Barbara Franke designed the study. Marjolein van Donkelaar managed literature searches, analyses and wrote the first draft of the manuscript. Elena Shumskaya was responsible for data management, data preparation and data quality control. Marjolein van Donkelaar, Janita Bralten and Martine Hoogman where involved in the statistical analysis. All authors contributed to and have approved the final manuscript.

\section{Conflicts of interest}

Barbara Franke discloses having received educational speaking fees from Merz and Shire. Jan K Buitelaar has been in the past 3 years a consultant to / member of advisory board of / and/or speaker for Janssen Cilag BV, Eli Lilly, Lundbeck, Shire, Roche, Novartis, and Servier. He is not an employee of any of these companies, and not a stock shareholder of any of these companies. He has no other financial or material support, including expert testimony, patents, royalties. None of the other authors report conflicts of interest.

\section{Acknowledgements}

The authors would like to thank the Genetics of Multifactorial Diseases group of the Department of Human Genetics, Radboud university medical center, for their valuable contributions to genetic data collection, preparation and management.

\section{Appendix A. Supporting information}

Supplementary data associated with this article can be found in the online version at $10.1016 / j$.euroneuro.2017.11. 016.

\section{References}

Abecasis, G.R., Auton, A., Brooks, L.D., DePristo, M.A., Durbin, R.M., Handsaker, R.E., Kang, H.M., Marth, G.T., McVean, G.A., 2012. An integrated map of genetic variation from 1092 human genomes. Nature 491, 56-65.

Agid, O., Shapira, B., Zislin, J., Ritsner, M., Hanin, B., Murad, H., Troudart, T., Bloch, M., Heresco-Levy, U., Lerer, B., 1999. Environment and vulnerability to major psychiatric illness: a case control study of early parental loss in major depression, bipolar disorder and schizophrenia. Mol. Psychiatry 4, 163-172.

Alink, L.R., Cicchetti, D., Kim, J., Rogosch, F.A., 2012. Longitudinal associations among child maltreatment, social functioning, and cortisol regulation. Dev. Psychol. 48, 224-236.

Baillargeon, R.H., Zoccolillo, M., Keenan, K., Côté, S., Pérusse, D., Wu, H.-X., Boivin, M., Tremblay, R.E., 2007. Gender differences in physical aggression: a prospective population-based survey of children before and after 2 years of age. Dev. Psychol. 43, 13-26.

Baker, L.A., Raine, A., Liu, J., Jacobson, K.C., 2008. Differential genetic and environmental influences on reactive and proactive aggression in children. J. Abnorm. Child Psychol. 36, 1265-1278.

Baron, R.A., Richardson, D.S., 1994. Human Aggression, 2nd ed. Plenum Press, New York.

Bevilacqua, L., Doly, S., Kaprio, J., Yuan, Q., Tikkanen, R., Paunio, T., Zhou, Z., Wedenoja, J., Maroteaux, L., Diaz, S., et al., 2010. A population-specific HTR2B stop codon predisposes to severe impulsivity. Nature 468, 1061-1066.

Bjork, J., 2000. Differential behavioral effects of plasma tryptophan depletion and loading in aggressive and nonaggressive men. Neuropsychopharmacology 22, 357-369.

Bogdan, R., Salmeron, B.J., Carey, C.E., Agrawal, A., Calhoun, V.D., Garavan, H., Hariri, A.R., Heinz, A., Hill, M.N., Holmes, A., Kalin, N.H., Goldman, D., 2017. Imaging genetics and genomics in psychiatry: a critical review of progress and potential. Biol. Psychiatry.

Book, A.S., Starzyk, K.B., Quinsey, V.L., 2001. The relationship between testosterone and aggression: a meta-analysis. Aggress. Violent Behav. 6, 579-599.

Bralten, J., Arias-Vásquez, A., Makkinje, R., Veltman, J.A., Brunner, H.G., Fernández, G., Rijpkema, M., Franke, B., 2011. Association of the alzheimer's gene SORL1 with hippocampal volume in young, healthy adults. Am. J. Psychiatry 168, 1083-1089.

Bralten, J., Franke, B., Waldman, I., Rommelse, N., Hartman, C., Asherson, P., Banaschewski, T., Ebstein, R.P., Gill, M., Miranda, A., Oades, R.D., Roeyers, H., Rothenberger, A., Sergeant, J.A., Oosterlaan, J., Sonuga-Barke, E., Steinhausen, H.C., Faraone, S.V., Buitelaar, J.K., AriasVasquez, A., 2013. Candidate genetic pathways for attention-deficit/hyperactivity disorder (ADHD) show association to hyperactive/impulsive symptoms in children with ADHD. J. Am. Acad. Child Adolesc. Psychiatry 52, 1204-1212 (e1201).

Brendgen, M., Dionne, G., Girard, A., Boivin, M., Vitaro, F., Perusse, D., 2005. Examining genetic and environmental effects on social aggression: a study of 6-year-old twins. Child Dev. 76, 930-946.

Brown, G.L., Goodwin, F.K., Ballenger, J.C., Goyer, P.F., Major, L.F., 1979. Aggression in humans correlates with cerebrospinal fluid amine metabolites. Psychiatry Res. 1, 131-139.

Brown, G.L., McGarvey, E.L., Shirtcliff, E.A., Keller, A., Granger, D.A., Flavin, K., 2008. Salivary cortisol, dehydroepiandrosterone, and testosterone interrelationships in healthy young males: a pilot study with implications for studies of aggressive behavior. Psychiatry Res. 159, 67-76.

Brugman, S., Cornet, L.J., Smeijers, D., Smeets, K., Oostermeijer, S., Buitelaar, J.K., Verkes, R.J., Lobbestael, J., de Kogel, C.H., Jansen, L.M., 2016. Examining the reactive proactive questionnaire in adults in forensic and non-forensic settings: a variable- and person-based approach. Aggress. Behav. 
Brugman, S., Lobbestael, J., Arntz, A., Cima, M., Schuhmann, T., Dambacher, F., Sack, A.T., 2015. Identifying cognitive predictors of reactive and proactive aggression. Aggress. Behav. 41, 51-64.

Brunner, H., Nelen, M., Breakefield, X., Ropers, H., van Oost, B., 1993. Abnormal behavior associated with a point mutation in the structural gene for monoamine oxidase A. Science 262, 578-580.

Bubier, J.L., Drabick, D.A., 2009. Co-occurring anxiety and disruptive behavior disorders: the roles of anxious symptoms, reactive aggression, and shared risk processes. Clin. Psychol. Rev. 29, 658-669.

Burger, H.G., 2002. Androgen production in women. Fertil. Steril. 77, 3-5.

Byrd, A.L., Manuck, S.B., 2014. MAOA, childhood maltreatment, and antisocial behavior: meta-analysis of a gene-environment interaction. Biol. Psychiatry 75, 9-17.

Card, N.A., Stucky, B.D., Sawalani, G.M., Little, T.D., 2008. Direct and indirect aggression during childhood and adolescence: a meta-analytic review of gender differences, intercorrelations, and relations to maladjustment. Child Dev. 79, 1185-1229.

Caspi, A., 2002. Role of genotype in the cycle of violence in maltreated children. Science 297, 851-854.

Chichinadze, K.N., Domianidze, T.R., Matitaishvili, T.T., Chichinadze, N.K., Lazarashvili, A.G., 2010. Possible relation of plasma testosterone level to aggressive behavior of male prisoners. Bull. Exp. Biol. Med. 149, 7-9.

Cima, M., Raine, A., 2009. Distinct characteristics of psychopathy relate to different subtypes of aggression. Pers. Individ. Differ. 47, 835-840.

Cima, M., Raine, A., Meesters, C., Popma, A., 2013. Validation of the Dutch Reactive Proactive Questionnaire (RPQ): differential correlates of reactive and proactive aggression from childhood to adulthood. Aggress. Behav. 39, 99-113.

Coccaro, E.F., Lee, R., 2010. Cerebrospinal fluid 5-hydroxyindolacetic acid and homovanillic acid: reciprocal relationships with impulsive aggression in human subjects. J. Neural Transm. 117, 241-248.

Collett, B.R., Ohan, J.L., Myers, K.M., 2003. Ten-year review of rating scales. VI: scales assessing externalizing behaviors. J. Am. Acad. Child Adolesc. Psychiatry 42, 1143-1170.

Connor, D.F., Steingard, R.J., Anderson, J.J., Melloni Jr., R.H., 2003. Gender differences in reactive and proactive aggression. Child psychiatry Human. Dev. 33, 279-294.

Côté, S.M., 2007. Sex differences in physical and indirect aggression: a developmental perspective. Eur. J. Crim. Policy Res. 13, 183-200.

Costa, A., la Fougere, C., Pogarell, O., Moller, H.J., Riedel, M., Ettinger, U., 2012. Impulsivity is related to striatal dopamine transporter availability in healthy males. Psychiatry Res.

de Leeuw, C.A., Mooij, J.M., Heskes, T., Posthuma, D., 2015. MAGMA: generalized gene-set analysis of GWAS data. PLoS Comput. Biol. 11, e1004219.

Dodge, K.A., Coie, J.D., 1987. Social-information-processing factors in reactive and proactive aggression in children's peer groups. J. Pers. Social. Psychol. 53, 1146-1158.

Éthier, L.S., Lemelin, J.-P., Lacharité, C., 2004. A longitudinal study of the effects of chronic maltreatment on children's behavioral and emotional problems. Child Abus. Negl. 28, 1265-1278.

Fergusson, D.M., John Horwood, L., Ridder, E.M., 2005. Show me the child at seven: the consequences of conduct problems in childhood for psychosocial functioning in adulthood. J. Child Psychol. Psychiatry 46, 837-849.

Fernandez-Castillo, N., Cormand, B., 2016. Aggressive behavior in humans: genes and pathways identified through association studies. Am. J. Med. Genet. Part B, Neuropsychiatr. Genet.: Off. Publ. Int. Soc. Psychiatr. Genet. 171, 676-696.

Ficks, C.A., Waldman, I.D., 2014. Candidate genes for aggression and antisocial behavior: a meta-analysis of association studies of the 5HTTLPR and MAOA-uVNTR. Behav. Genet 44, 427-444.
Fonagy, P., 2006. Early-life trauma and the psychogenesis and prevention of violence. Ann. New Y. Acad. Sci. 1036, 181-200.

Franke, B., Vasquez, A.A., Veltman, J.A., Brunner, H.G., Rijpkema, M., Fernandez, G., 2010. Genetic variation in CACNA1C, a gene associated with bipolar disorder, influences brainstem rather than gray matter volume in healthy individuals. Biol. Psychiatry $68,586-588$.

Georgiev, A.V., Klimczuk, A.C.E., Traficonte, D.M., Maestripieri, D., 2013. When violence pays: a cost-benefit analysis of aggressive behavior in animals and humans. Evolut. Psychol. 11.

Gerritsen, L., Tendolkar, I., Franke, B., Vasquez, A.A., Kooijman, S., Buitelaar, J., Fernandez, G., Rijpkema, M., 2012. BDNF Val66Met genotype modulates the effect of childhood adversity on subgenual anterior cingulate cortex volume in healthy subjects. Mol. Psychiatry 17, 597-603.

Heim, C., Newport, D.J., Bonsall, R., Miller, A.H., Nemeroff, C.B., 2001. Altered pituitary-adrenal axis responses to provocative challenge tests in adult survivors of childhood abuse. Am. J. Psychiatry $158,575-581$.

Hill, J., 2002. Biological, psychological and social processes in the conduct disorders. J. Child Psychol. Psychiatry 43, 133-164.

Hill, A.L., Degnan, K.A., Calkins, S.D., Keane, S.P., 2006. Profiles of externalizing behavior problems for boys and girls across preschool: the roles of emotion regulation and inattention. Dev. Psychol. 42, 913-928.

Howie, B., Fuchsberger, C., Stephens, M., Marchini, J., Abecasis, G.R., 2012. Fast and accurate genotype imputation in genome-wide association studies through pre-phasing. Nat. Genet 44, 955-959.

$\mathrm{Hu}, \mathrm{Lt}$, Bentler, P.M., 1999. Cutoff criteria for fit indexes in covariance structure analysis: conventional criteria versus new alternatives. Struct. Equ. Model.: A Multidiscip. J. 6, 1-55.

Kempes, M., Matthys, W., de Vries, H., van Engeland, H., 2005. Reactive and proactive aggression in children: a review of theory, findings and the relevance for child and adolescent psychiatry. Eur. Adolesc. Psych. 14, 11-19.

Lesch, K.P., Araragi, N., Waider, J., van den Hove, D., Gutknecht, L., 2012. Targeting brain serotonin synthesis: insights into neurodevelopmental disorders with long-term outcomes related to negative emotionality, aggression and antisocial behaviour. Philos. Trans. R. Soc. B: Biol. Sci. 367, 2426-2443.

Li, Y., Willer, C.J., Ding, J., Scheet, P., Abecasis, G.R., 2010. MaCH: using sequence and genotype data to estimate haplotypes and unobserved genotypes. Genet. Epidemiol. 34, 816-834.

Loney, B.R., Butler, M.A., Lima, E.N., Counts, C.A., Eckel, L.A., 2006. The relation between salivary cortisol, callous-unemotional traits, and conduct problems in an adolescent non-referred sample. J. Child Psychol. Psychiatry 47, 30-36.

Lopez-Duran, N.L., Olson, S.L., Hajal, N.J., Felt, B.T., Vazquez, D.M., 2008. Hypothalamic pituitary adrenal axis functioning in reactive and proactive aggression in children. J. Abnorm. Child Psychol. 37, 169-182.

Martin, J., Hamshere, M.L., Stergiakouli, E., O’Donovan, M.C., Thapar, A., 2014. Genetic risk for attention-deficit/hyperactivity disorder contributes to neurodevelopmental traits in the general population. Biol. Psychiatry 76, 664-671.

Middeldorp, C.M., Hammerschlag, A.R., Ouwens, K.G., Groen-Blokhuis, M.M., St Pourcain, B., Greven, C.U., Pappa, I., Tiesler, C.M., Ang, W., Nolte, I.M., Vilor-Tejedor, N., Bacelis, J., Ebejer, J.L., Zhao, H., Davies, G.E., Ehli, E.A., Evans, D.M., Fedko, I.O., Guxens, M., Hottenga, J.J., Hudziak, J.J., Jugessur, A., Kemp, J.P., Krapohl, E., Martin, N.G., Murcia, M., Myhre, R., Ormel, J., Ring, S.M., Standl, M., Stergiakouli, E., Stoltenberg, C., Thiering, E., Timpson, N.J., Trzaskowski, M., van der Most, P.J., Wang, C., Nyholt, D.R., Medland, S.E., Neale, B., Jacobsson, B., Sunyer, J., Hartman, C.A., Whitehouse, A.J., Pennell, C.E., Heinrich, J., Plomin, R., Davey Smith, G., Tiemeier, H., Posthuma, D., Boomsma, D.I., 2016. 
A genome-wide association meta-analysis of attention-deficit/hyperactivity disorder symptoms in population-based pediatric cohorts. J. Am. Acad. Child Adolesc. Psychiatry 55, 896-905 (e896).

Montoya, E.R., Terburg, D., Bos, P.A., van Honk, J., 2012. Testosterone, cortisol, and serotonin as key regulators of social aggression: a review and theoretical perspective. Motiv. Emot. 36, 65-73.

Naaijen, J., Bralten, J., Poelmans, G., Glennon, J.C., Franke, B., Buitelaar, J.K., 2017. Glutamatergic and GABAergic gene sets in attention-deficit/hyperactivity disorder: association to overlapping traits in ADHD and autism. Transl. Psychiatry 7, e999.

Nautiyal, K.M., Tanaka, K.F., Barr, M.M., Tritschler, L., Le Dantec, Y., David, D.J., Gardier, A.M., Blanco, C., Hen, R., Ahmari, S.E., 2015. Distinct Circuits Underlie the Effects of 5-HT1B Receptors on Aggression and Impulsivity. Neuron 86, 813-826.

Nelson, R.J., Trainor, B.C., 2007. Neural mechanisms of aggression. Nat. Rev. Neurosci. 8, 536-546.

Pavlov, K.A., Chistiakov, D.A., Chekhonin, V.P., 2012. Genetic determinants of aggression and impulsivity in humans. J Appl. Genet 53, 61-82.

Popma, A., Vermeiren, R., Geluk, C.A.M.L., Rinne, T., van den Brink, W., Knol, D.L., Jansen, L.M.C., van Engeland, H., Doreleijers, T.A.H., 2007. Cortisol moderates the relationship between testosterone and aggression in delinquent male adolescents. Biol. Psychiatry 61, 405-411.

Provencal, N., Booij, L., Tremblay, R.E., 2015. The developmental origins of chronic physical aggression: biological pathways triggered by early life adversity. J. Exp. Biol. 218, 123-133.

Raine, A., Dodge, K., Loeber, R., Gatzke-Kopp, L., Lynam, D., Reynolds, C., Stouthamer-Loeber, M., Liu, J., 2006. The reactive-proactive aggression questionnaire: differential correlates of reactive and proactive aggression in adolescent boys. Aggress. Behav. 32, 159-171.

Reef, J., Diamantopoulou, S., van Meurs, I., Verhulst, F.C., van der Ende, J., 2010. Developmental trajectories of child to adolescent externalizing behavior and adult DSM-IV disorder: results of a 24-year longitudinal study. Social. Psychiatry Psychiatr. Epidemiol. 46, 1233-1241.

Riglin, L., Collishaw, S., Thapar, A.K., Dalsgaard, S., Langley, K., Smith, G.D., Stergiakouli, E., Maughan, B., O’Donovan, M.C., Thapar, A., 2016. Association of genetic risk variants with attention-deficit/hyperactivity disorder trajectories in the general population. JAMA Psychiatry 73, 1285-1292.

Robinson, E.B., St Pourcain, B., Anttila, V., Kosmicki, J.A., Bulik-Sullivan, B., Grove, J., Maller, J., Samocha, K.E., Sanders, S.J., Ripke, S., Martin, J., Hollegaard, M.V., Werge, T., Hougaard, D.M., Neale, B.M., Evans, D.M., Skuse, D., Mortensen, P.B., Borglum, A.D., Ronald, A., Smith, G.D., Daly, M.J., 2016. Genetic risk for autism spectrum disorders and neuropsychiatric variation in the general population. Nat. Genet 48, 552-555.

Rosell, D.R., Siever, L.J., 2015. The neurobiology of aggression and violence. CNS Spectrums 20, 254-279.

Shirtcliff, E.A., Granger, D.A., Booth, A., Johnson, D., 2005. Low salivary cortisol levels and externalizing behavior problems in youth. Dev. Psychopathol. 17.

Salmivalli, C., Nieminen, E., 2002. Proactive and reactive aggression among school bullies, victims, and bully-victims. Aggress. Behav. 28, 30-44.

Smeets, K.C., Oostermeijer, S., Lappenschaar, M., Cohn, M., van der Meer, J.M., Popma, A., Jansen, L.M., Rommelse, N.N., Scheepers, F.E., Buitelaar, J.K., 2016. Are proactive and reactive aggression meaningful distinctions in adolescents? a variable- and person-based approach. J Abnorm Child Psychol.

Stanford, M.S., Houston, R.J., Mathias, C.W., Villemarette-Pittman, N.R., Helfritz, L.E., Conklin, S.M., 2003. Characterizing aggressive behavior. Assessment 10, 183-190.
Stephenson, Z., Woodhams, J., Cooke, C., 2014. Sex differences in predictors of violent and non-violent juvenile offending. Aggress. Behav. 40, 165-177.

Terburg, D., Morgan, B., van Honk, J., 2009. The testosterone-cortisol ratio: a hormonal marker for proneness to social aggression. Int. J. Law Psychiatry 32, 216-223.

Thompson, P.M., Stein, J.L., Medland, S.E., Hibar, D.P., Vasquez, A.A., Renteria, M.E., Toro, R., Jahanshad, N., Schumann, G., Franke, B., Wright, M.J., Martin, N.G., Agartz, I., Alda, M., Alhusaini, S., Almasy, L., Almeida, J., Alpert, K., Andreasen, N.C., Andreassen, O.A., Apostolova, L.G., Appel, K., Armstrong, N.J., Aribisala, B., Bastin, M.E., Bauer, M., Bearden, C.E., Bergmann, O., Binder, E.B., Blangero, J., Bockholt, H.J., Boen, E., Bois, C., Boomsma, D.I., Booth, T., Bowman, I.J., Bralten, J., Brouwer, R.M., Brunner, H.G., Brohawn, D.G., Buckner, R.L., Buitelaar, J., Bulayeva, K., Bustillo, J.R., Calhoun, V.D., Cannon, D.M., Cantor, R.M., Carless, M.A., Caseras, X., Cavalleri, G.L., Chakravarty, M.M., Chang, K.D., Ching, C.R., Christoforou, A., Cichon, S., Clark, V.P., Conrod, P., Coppola, G., Crespo-Facorro, B., Curran, J.E., Czisch, M., Deary, I.J., de Geus, E.J., den Braber, A., Delvecchio, G., Depondt, C., de Haan, L., de Zubicaray, G.I., Dima, D., Dimitrova, R., Djurovic, S., Dong, H., Donohoe, G., Duggirala, R., Dyer, T.D., Ehrlich, S., Ekman, C.J., Elvsashagen, T., Emsell, L., Erk, S., Espeseth, T., Fagerness, J., Fears, S., Fedko, I., Fernandez, G., Fisher, S.E., Foroud, T., Fox, P.T., Francks, C., Frangou, S., Frey, E.M., Frodl, T., Frouin, V., Garavan, H., Giddaluru, S., Glahn, D.C., Godlewska, B., Goldstein, R.Z., Gollub, R.L., Grabe, H.J., Grimm, O., Gruber, O., Guadalupe, T., Gur, R.E., Gur, R.C., Goring, H.H., Hagenaars, S., Hajek, T., Hall, G.B., Hall, J., Hardy, J., Hartman, C.A., Hass, J., Hatton, S.N., Haukvik, U.K., Hegenscheid, K., Heinz, A., Hickie, I.B., Ho, B.C., Hoehn, D., Hoekstra, P.J., Hollinshead, M., Holmes, A.J., Homuth, G., Hoogman, M., Hong, L.E., Hosten, N., Hottenga, J.J., Hulshoff Pol, H.E., Hwang, K.S., Jack Jr., C.R., Jenkinson, M., Johnston, C., Jonsson, E.G., Kahn, R.S., Kasperaviciute, D., Kelly, S., Kim, S., Kochunov, P., Koenders, L., Kramer, B., Kwok, J.B., Lagopoulos, J., Laje, G., Landen, M., Landman, B.A., Lauriello, J., Lawrie, S.M., Lee, P.H., Le Hellard, S., Lemaitre, H., Leonardo, C.D., Li, C.S., Liberg, B., Liewald, D.C., Liu, X., Lopez, L.M., Loth, E., Lourdusamy, A., Luciano, M., Macciardi, F., Machielsen, M.W., Macqueen, G.M., Malt, U.F., Mandl, R., Manoach, D.S., Martinot, J.L., Matarin, M., Mather, K.A., Mattheisen, M., Mattingsdal, M., Meyer-Lindenberg, A., McDonald, C., McIntosh, A.M., McMahon, F.J., McMahon, K.L., Meisenzahl, E., Melle, I., Milaneschi, Y., Mohnke, S., Montgomery, G.W., Morris, D.W., Moses, E.K., Mueller, B.A., Munoz Maniega, S., Muhleisen, T.W., Muller-Myhsok, B., Mwangi, B., Nauck, M., Nho, K., Nichols, T.E., Nilsson, L.G., Nugent, A.C., Nyberg, L., Olvera, R.L., Oosterlaan, J., Ophoff, R.A., Pandolfo, M., Papalampropoulou-Tsiridou, M., Papmeyer, M., Paus, T., Pausova, Z., Pearlson, G.D., Penninx, B.W., Peterson, C.P., Pfennig, A., Phillips, M., Pike, G.B., Poline, J.B., Potkin, S.G., Putz, B., Ramasamy, A., Rasmussen, J., Rietschel, M., Rijpkema, M., Risacher, S.L., Roffman, J.L., Roiz-Santianez, R., Romanczuk-Seiferth, N., Rose, E.J., Royle, N.A., Rujescu, D., Ryten, M., Sachdev, P.S., Salami, A., Satterthwaite, T.D., Savitz, J., Saykin, A.J., Scanlon, C., Schmaal, L., Schnack, H.G., Schork, A.J., Schulz, S.C., Schur, R., Seidman, L., Shen, L., Shoemaker, J.M., Simmons, A., Sisodiya, S.M., Smith, C., Smoller, J.W., Soares, J.C., Sponheim, S.R., Sprooten, E., Starr, J.M., Steen, V.M., Strakowski, S., Strike, L., Sussmann, J., Samann, P.G., Teumer, A., Toga, A.W., Tordesillas-Gutierrez, D., Trabzuni, D., Trost, S., Turner, J., Van den Heuvel, M., van der Wee, N.J., van Eijk, K., van Erp, T.G., van Haren, N.E., van 't Ent, D., van Tol, M.J., Valdes Hernandez, M.C., Veltman, D.J., Versace, A., Volzke, H., Walker, R., 
Walter, H., Wang, L., Wardlaw, J.M., Weale, M.E., Weiner, M.W., Wen, W., Westlye, L.T., Whalley, H.C., Whelan, C.D., White, T., Winkler, A.M., Wittfeld, K., Woldehawariat, G., Wolf, C., Zilles, D., Zwiers, M.P., Thalamuthu, A., Schofield, P.R., Freimer, N.B., Lawrence, N.S., Drevets, W., 2014. The ENIGMA Consortium: large-scale collaborative analyses of neuroimaging and genetic data. Brain Imaging Behav. 8, 153-182.

Tuvblad, C., Baker, L.A., 2011. Human Aggression Across the Lifespan, Advances in Genetics. Elsevier BV, pp. 171-214.

Tuvblad, C., Raine, A., Zheng, M., Baker, L.A., 2009. Genetic and environmental stability differs in reactive and proactive aggression. Aggress. Behav. 35, 437-452.

van Bokhoven, I., Van Goozen, S.H.M., van Engeland, H., Schaal, B., Arseneault, L., Séguin, J.R., Nagin, D.S., Vitaro, F., Tremblay, R.E., 2004. Salivary cortisol and aggression in a population-based longitudinal study of adolescent males. J. Neural Transm. 112, 1083-1096.

Vassos, E., Collier, D.A., Fazel, S., 2014. Systematic meta-analyses and field synopsis of genetic association studies of violence and aggression. Mol. Psychiatry 19, 471-477.

Veenema, A.H., 2009. Early life stress, the development of aggression and neuroendocrine and neurobiological correlates: what can we learn from animal models? Front. Neuroendocr. 30, 497-518.
Veroude, K., Zhang-James, Y., Fernandez-Castillo, N., Bakker, M.J., Cormand, B., Faraone, S.V., 2016. Genetics of aggressive behavior: an overview. Am. J. Med. Genet. Part B, Neuropsychiatr. Genet.: Off. Publ. Int. Soc. Psychiatr. Genet. 171B, 3-43.

Waltes, R., Chiocchetti, A.G., Freitag, C.M., 2015. The neurobiological basis of human aggression: A review on genetic and epigenetic mechanisms.

Wang, P., Niv, S., Tuvblad, C., Raine, A., Baker, L.A., 2013. The genetic and environmental overlap between aggressive and non-aggressive antisocial behavior in children and adolescents using the self-report delinquency interview (SR-DI). J. Crim. Justice 41, 277-284.

WHO, 2007. Third milestones of a global campaign for violence prevention report, 2007: Scaling up., Geneva, Switserland.

Yu, Y.-Z., Shi, J.-X., 2009. Relationship between levels of testosterone and cortisol in saliva and aggressive behaviors of adolescents. Biomed. Environ. Sci. 22, 44-49.

Zhang-James, Y., Faraone, S.V., 2016. Genetic architecture for human aggression: a study of gene-phenotype relationship in OMIM. Am. J. Med. Genet. Part B: Neuropsychiatr. Genet. 171, 641-649. 